\title{
Immunotherapy for patients with advanced pancreatic carcinoma: a promising treatment
}

\author{
Bin Zhang ${ }^{1,2, *}$, Yuhao Dong ${ }^{1,2, *}$, Jing Liu ${ }^{1,2}$, Zhouyang Lian ${ }^{1,2}$, Long Liang ${ }^{1,2}$, Wenbo \\ Chen $^{3}$, Xiaoning Luo ${ }^{1,2}$, Shufang Pei ${ }^{1,2}$, Xiaokai Mo ${ }^{1,2}$, Lu Zhang ${ }^{1,2}$, Wenhui Huang ${ }^{1,4}$, \\ Fusheng Ouyang ${ }^{1,2}$, Baoliang Guo ${ }^{1,2}$, Changhong Liang ${ }^{1}$ and Shuixing Zhang ${ }^{1}$ \\ ${ }^{1}$ Department of Radiology, Guangdong General Hospital/Guangdong Academy of Medical Sciences, Guangzhou, Guangdong, \\ P.R. China \\ ${ }^{2}$ Graduate College, Southern Medical University, Guangzhou, Guangdong, P.R. China \\ ${ }^{3}$ Department of Radiology, Huizhou Municipal Central Hospital, Huizhou, Guangdong, P.R. China \\ ${ }^{4}$ School of medicine, South China University of Technology, Guangzhou, Guangdong, P.R. China \\ * These authors have contributed equally to this work \\ Correspondence to: Shuixing Zhang, email: shui7515@126.com \\ Keywords: immunotherapy; chemotherapy; advanced pancreatic cancer; adverse events; overall survival \\ Received: July 15, $2016 \quad$ Accepted: December 12, $2016 \quad$ Published: December 15, 2016
}

\section{ABSTRACT}

There are limited data on the safety and efficacy of immunotherapy for patients with advanced pancreatic cancer (APC). A meta-analysis of single-arm trials is proposed to assess the efficacy and safety of immunotherapy for APC. Eighteen relevant studies involving 527 patients were identified. The pooled disease control rate (DCR), overall survival (OS), progression free survival (PFS), and 1-year survival rate were estimated as $59.32 \%, 7.90$ months, 4.25 months, and $30.12 \%$, respectively. Subgroup analysis showed that the pooled OS, PFS, and 1-year survival rate were significantly higher for autologous activated lymphocyte therapy compared with peptide-based vaccine therapy (OS: 8.28 months vs. 7.40 months; PFS: 6.04 months vs. 3.86 months; 1 -year survival rate: $37.17 \%$ vs. $19.74 \%$ ). Another subgroup analysis demonstrated that the pooled endpoints were estimated as obviously higher for immunotherapy plus chemotherapy compared with immunotherapy alone (DCR: 62.51\% vs. $47.63 \%$; OS: 8.67 months vs. 4.91 months; PFS: 4.91 months vs. 3.34 months; 1-year survival rate: $32.32 \%$ vs. $21.43 \%$ ). Of the included trials, seven trials reported no treatment related adverse events, five trials reported (16.6 \pm 3.9$) \%$ grade 3 adverse events and no grade 4 adverse events. In conclusion, immunotherapy is safe and effective in the treatment of APC.

\section{INTRODUCTION}

Pancreatic cancer (PC) is the fourth most common cause of cancer death worldwide, which is characterized by an extremely poor survival rate [1]. Up to $80 \%$ deaths occur

within the first year of diagnosis and the overall 5 -year mortality rate is over $95 \%[2,3]$. Although surgical resection is the only potentially curative approach, only $10-20 \%$ of pancreatic tumors are operable, about $40 \%$ are locally advanced, unresectable and $45 \%$ are with metastases $[4,5]$. Usually, patients with advanced pancreatic cancer (APC) are unable to resort to surgery, the treatment alternatives of whom are very limited, with gemcitabine as the current first-line treatment [6]. However, patients received gemcitabine had a overall survival (OS) of around 6 months and a one-year survival $\leq 20 \%$ [7]. Once APC patients are resistant to gemcitabine therapy, there is barely effective treatment. New treatment strategies are therefore urgently required.

Recently, immune cell-based cancer therapy has been attempted as an alternative treatment option for anticancer therapy [8]. It eliminates cancer cells by modulating the immune system to suppress cancer by active (potentiating the patient's intrinsic immune system against cancer cells ) and passive (administering extrinsic 
man-made immune system components ) immunotherapy [9]. Immunotherapy has an advantage over chemo(radio) therapies due to its specificity against tumor without hurting normal tissue [10]. Immunotherapeutic methods to PC included the administration of antibodies [11], cytokines [12], peptide vaccines [6,13-18], and autologous activated lymphocyte (e.g. dendritic cells, lymphokine activated killer cells, and cytotoxic T-lymphocyte) therapies [10, 19-24]. Despite the limited benefit of gemcitabine, it may enhance responses to specific vaccines or synergize immune system stimulators [22]. Hence, combining gemcitabine with immunotherapy for APC patients was used in most clinical trials. However, these published trials have been small with consistent results, precluding robust estimates of benefit.

To assess the benefit of immunotherapy in the treatment of patients with APC neutrally, we would like to perform a published data meta-analysis of all relevant single-arm trials.

\section{RESULTS}

\section{Trials}

A total of 18 trials involving 527 patients met the inclusion criteria were enrolled in this study (Figure 1). It included seven trials (295 patients) of autologous activated lymphocyte therapies, eight trials (170 patients) of peptide-based vaccine therapy, one trial (34 patients) of monoclonal antibody plus gemcitabine, one trial (16 patients) of cytokine-induced killer (CIK) and one trial (12 patients) of gene-mediated cytotoxic immunotherapy (GMCI). There were 14 trials (454 patients) used immunotherapy plus chemotherapy, only four trials (73 patients) used immunotherapy alone. Table 1 shows the details of trial designs, publication year, number of patients, female/male ratio, treatment schedules, and study end points.

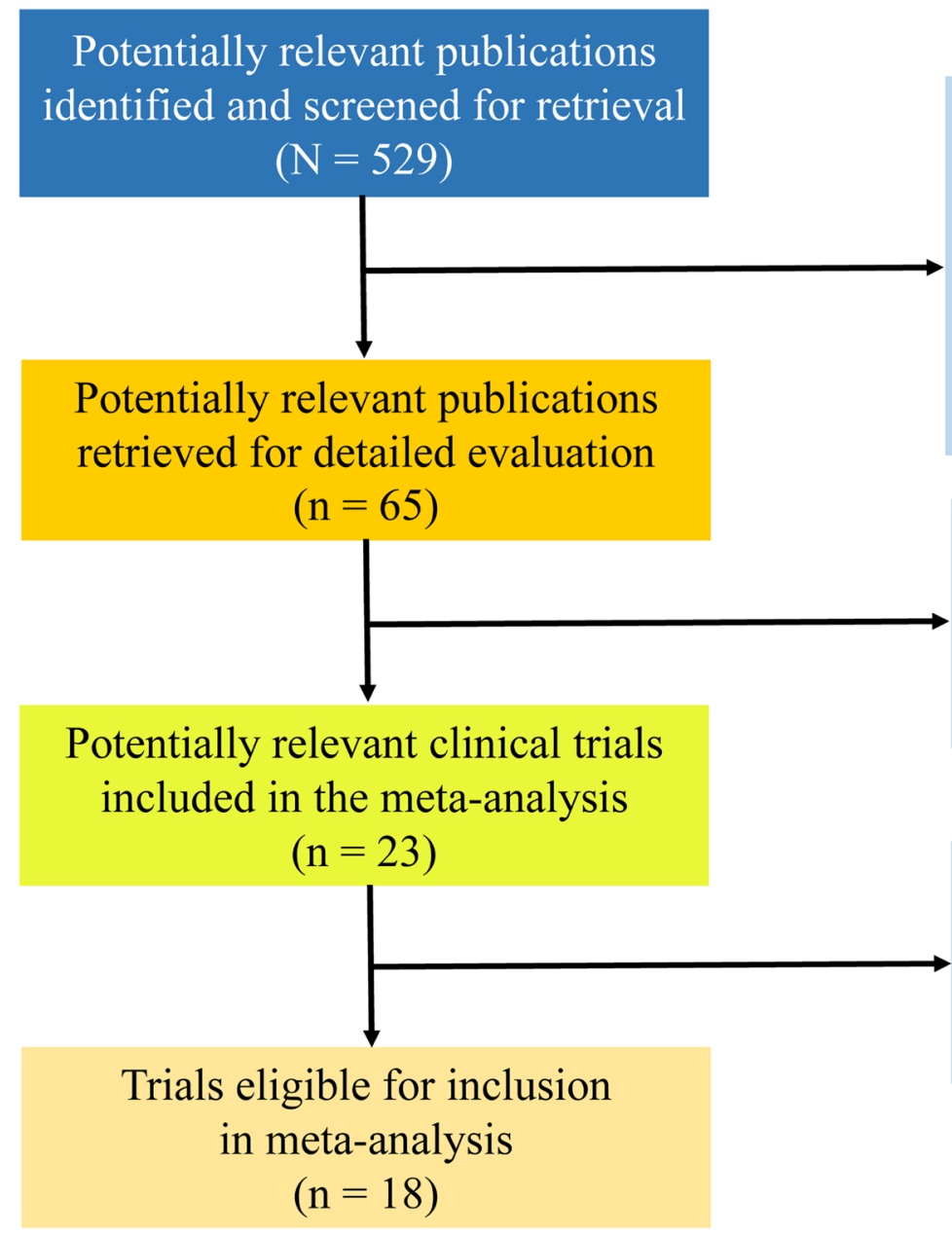

Publications excluded $(n=464)$

Reasons: Reviews

No abstracts available

Preclinical trials

Chemotherapy only

Animal experiment

Tutorials, pharmacologic trials or methodological trials

Publications excluded $(n=42)$

Reasons: Animal experiment

Did not analyze endpoints

Did not include immunotherapy

Including resectable pancreatic cancer

Trials excluded from meta-analysis $(n=5)$

Reasons: Endpoints without 95\%CI $(n=3)$

Mean value instead of median

value for endpoints $(n=1)$

Confounded trial $(n=1)$

Figure 1: Study flowchart. 
Table 1: Detailed data of the 18 trials included in this meta-analysis

\begin{tabular}{|c|c|c|c|c|c|c|}
\hline Trial & $\begin{array}{l}\text { study } \\
\text { design }\end{array}$ & $\begin{array}{l}\text { No. of } \\
\text { patients }\end{array}$ & $\begin{array}{l}\mathbf{F} / \mathbf{M} \\
\text { ratio }\end{array}$ & Age & Treatment protocol & Study endpoints \\
\hline KONDO (2008) & NA & 20 & $6 / 14$ & 63.4 & MUC1-DC+CTL & $\begin{array}{l}\text { DCR, OS, PFS, 1-year survival } \\
\text { rate, toxicity }\end{array}$ \\
\hline $\begin{array}{l}\text { Shindo } \\
(2014)\end{array}$ & Phase II & 42 & $21 / 21$ & 63.1 & MUC1-DC+CTL+ GEM & $\begin{array}{l}\text { DCR,MST, 1-year survival rate, } \\
\text {, toxicity }\end{array}$ \\
\hline $\begin{array}{l}\text { Hirooka } \\
(2009)\end{array}$ & Phase I & 5 & $4 / 1$ & 57.2 & $\mathrm{DC}+\mathrm{CTL}+\mathrm{GEM}$ & $\begin{array}{l}\text { DCR,PFS,OS,1-year survival } \\
\text { rate, toxicity }\end{array}$ \\
\hline $\begin{array}{l}\text { Gansauge } \\
(2013)\end{array}$ & Phase I/II & 134 & $58 / 76$ & 63.9 & LANEX-DC+GEM & $\begin{array}{l}\text { DCR, OS, 1-year survival rate, } \\
\text { toxicity }\end{array}$ \\
\hline $\begin{array}{l}\text { Kimura } \\
(2011)\end{array}$ & Phase I & 49 & $7 / 42$ & 61.7 & $\mathrm{DC}+\mathrm{LAK}+\mathrm{GEM} / \mathrm{S}-1$ & $\begin{array}{l}\text { DCR, OS, 1-year survival rate, } \\
\text { toxicity }\end{array}$ \\
\hline $\begin{array}{l}\text { Aglietta } \\
(2014)\end{array}$ & Phase I & 34 & $12 / 22$ & 59.5 & Tremelimumab +GEM & OS, toxicity \\
\hline $\begin{array}{l}\text { Aguilar } \\
(2015)\end{array}$ & Phase I & 12 & NA & 65.6 & GMCI+chemoradiation & $\begin{array}{l}\text { DCR, OS, PFS, 1-year survival } \\
\text { rate, toxicity }\end{array}$ \\
\hline $\begin{array}{l}\text { Asahara } \\
(2013)\end{array}$ & Phase I & 31 & $14 / 17$ & 61.3 & HLA-A24 peptide vaccine & $\begin{array}{l}\text { DCR, PFS, OS,1-year survival } \\
\text { rate, toxicity }\end{array}$ \\
\hline $\begin{array}{l}\text { Kameshima } \\
(2013)\end{array}$ & NA & 6 & $3 / 3$ & 61.2 & Survivin-2B80-88 peptide & DCR \\
\hline $\begin{array}{l}\text { Chung } \\
(2014)\end{array}$ & Phase II & 16 & NA & 59.5 & CIK cells & $\begin{array}{l}\text { DCR, OS, PFS, 1-year survival } \\
\text { rate, QoL, toxicity }\end{array}$ \\
\hline $\begin{array}{l}\text { Suzuki } \\
(2014)\end{array}$ & Phase I & 9 & $5 / 4$ & 61.8 & $\mathrm{KIF} 20 \mathrm{~A}+\mathrm{GEM}$ & $\begin{array}{l}\text { DCR,PFS,OS,1-year survival } \\
\text { rate, toxicity }\end{array}$ \\
\hline $\begin{array}{l}\text { Nishida } \\
(2014)\end{array}$ & Phase I & 31 & $15 / 17$ & 60.0 & WT1 peptide+GEM & $\begin{array}{l}\text { DCR,PFS,OS,1-year survival } \\
\text { rate, toxicity }\end{array}$ \\
\hline $\begin{array}{l}\text { STAFF } \\
(2014)\end{array}$ & Phase III & 21 & $7 / 14$ & 66.1 & GV1001+GEM & $\begin{array}{l}\text { DCR,PFS,OS,1-year survival } \\
\text { rate, toxicity }\end{array}$ \\
\hline $\begin{array}{l}\text { Miyazawa } \\
(2010)\end{array}$ & Phase I & 18 & $4 / 14$ & 65.3 & VEGFR2-169+GEM & DCR, OS, PFS, toxicity \\
\hline YUTANI (2013) & Phase II & 41 & $14 / 27$ & 61.0 & $\begin{array}{l}\text { Personalized peptide } \\
\text { vaccines }\end{array}$ & $\begin{array}{l}\text { DCR, MST, 1-year survival rate, } \\
\text { toxicity }\end{array}$ \\
\hline $\begin{array}{l}\text { Yanagimoto } \\
(2007)\end{array}$ & Phase I & 13 & $4 / 9$ & 62.3 & $\begin{array}{l}\text { Personalized peptide } \\
\text { vaccines }\end{array}$ & $\begin{array}{l}\text { DCR, OS, PFS, 1-year survival } \\
\text { rate, toxicity }\end{array}$ \\
\hline $\begin{array}{l}\text { NAKAMURA } \\
\text { (2009) }\end{array}$ & Phase I/II & 17 & $10 / 7$ & 63.0 & $\mathrm{DC} \pm \mathrm{LAK}+\mathrm{GEM}$ & OS, 1-year survival rate \\
\hline $\begin{array}{l}\text { KANEKO } \\
(2005)\end{array}$ & Phase II & 28 & $9 / 17$ & 63.9 & $\mathrm{DC} / \mathrm{LAK}+\mathrm{GEM}$ & DCR, OS, toxicity \\
\hline
\end{tabular}

Note: $\mathrm{F} / \mathrm{M}=$ Female/Male $\mathrm{NA}=$ Not Available $\mathrm{DC}=$ Dendritic cells $\mathrm{CTL}=$ cytotoxic T-lymphocyte $\mathrm{LAK}=$

lymphokine-activated killer lymphocytes GEM = Gemcitabine CIK = Cytokine-induced killer DCR = Disease Control Rate $\mathrm{PFS}=$ Progression-Free Survival OS = Overall Survival QoL = Quality of Life WT1 = Wilms Tumor Gene

\section{Disease control rate}

Disease control rate, defined as additive rates of complete response, partial response and stable disease, which could be calculated from all trials but two. Response classification was based on the Response Evaluation
Criteria in Solid Tumors (RECIST). A total of 476 (90\%) patients' response data were available, of which, 290 (61\%) patients received response. The pooled DCR for immunotherapy and/or chemotherapy was estimated as $59.32 \%$ (95\% CI: $51.74 \%$ to $66.90 \%$ ) (Figure 2). However, significant heterogeneity was observed between the trials $\left(\mathrm{I}^{2}=63 \%, P<0.001\right)$. Subgroup analysis by the type of 
immunotherapy showed that the DCR of peptide-based vaccine therapy $\left(69.0 \%, 95 \% \mathrm{CI}: 62.10 \%\right.$ to $75.89 \%$; $\mathrm{I}^{2}=$ $0 \%, P=0.900)$ increased by more than $34 \%$ as compared to autologous activated lymphocyte therapy $(51.34 \%$, 95\%CI: $41.14 \%$ to $\left.61.55 \% ; \mathrm{I}^{2}=58.4 \%, P=0.035\right)$ (Figure 2). Another subgroup analysis by the combination with or without chemotherapy indicated that the DCR for immunotherapy plus chemotherapy $(62.51 \%, 55.88 \%$ to $\left.69.14 \% ; \mathrm{I}^{2}=41.4 \%, P=0.067\right)$ was $31 \%$ higher than immunotherapy alone $(47.63 \%, 95 \% \mathrm{CI}: 21.25 \%$ to $\left.74.01 \% ; \mathrm{I}^{2}=82.7 \%, P=0.001\right)$ (Figure 3 ).

\section{Progression free survival}

Progression-free survival (PFS) time was reported in nine trials (158 patients). The pooled PFS for immunotherapy was estimated to be 4.25 months (95\%CI: 2.98 to 5.51 ), but with significant heterogeneity between individual trials $\left(\mathrm{I}^{2}=89.2 \%, P<0.001\right)$ (Figure 4). Subgroup analysis by the type of immunotherapy showed that the PFS was significant longer for autologous activated lymphocyte therapy (6.04 months, 95\%CI: -0.12 to $\left.12.20 ; \mathrm{I}^{2}=0 \%, P=0.963\right)$ than peptide-based vaccine therapy (3.86 months, $95 \% \mathrm{CI}: 2.71$ to $5.01 ; \mathrm{I}^{2}=76.8 \%, P$ $=0.002$ ) (Figure 4). Subgroup analysis according to the combination with or without chemotherapy indicated that the PFS was much longer for immunotherapy combined with chemotherapy (4.91 months, $95 \% \mathrm{CI}$ : 3.51 to 6.32 ; $\left.\mathrm{I}^{2}=0 \%, P=0.695\right)$ compared with immunotherapy alone (3.34 months, $95 \% \mathrm{CI}: 1.05$ to $5.63 ; \mathrm{I}^{2}=87 \%, P<0.001$ ) (Figure 5).

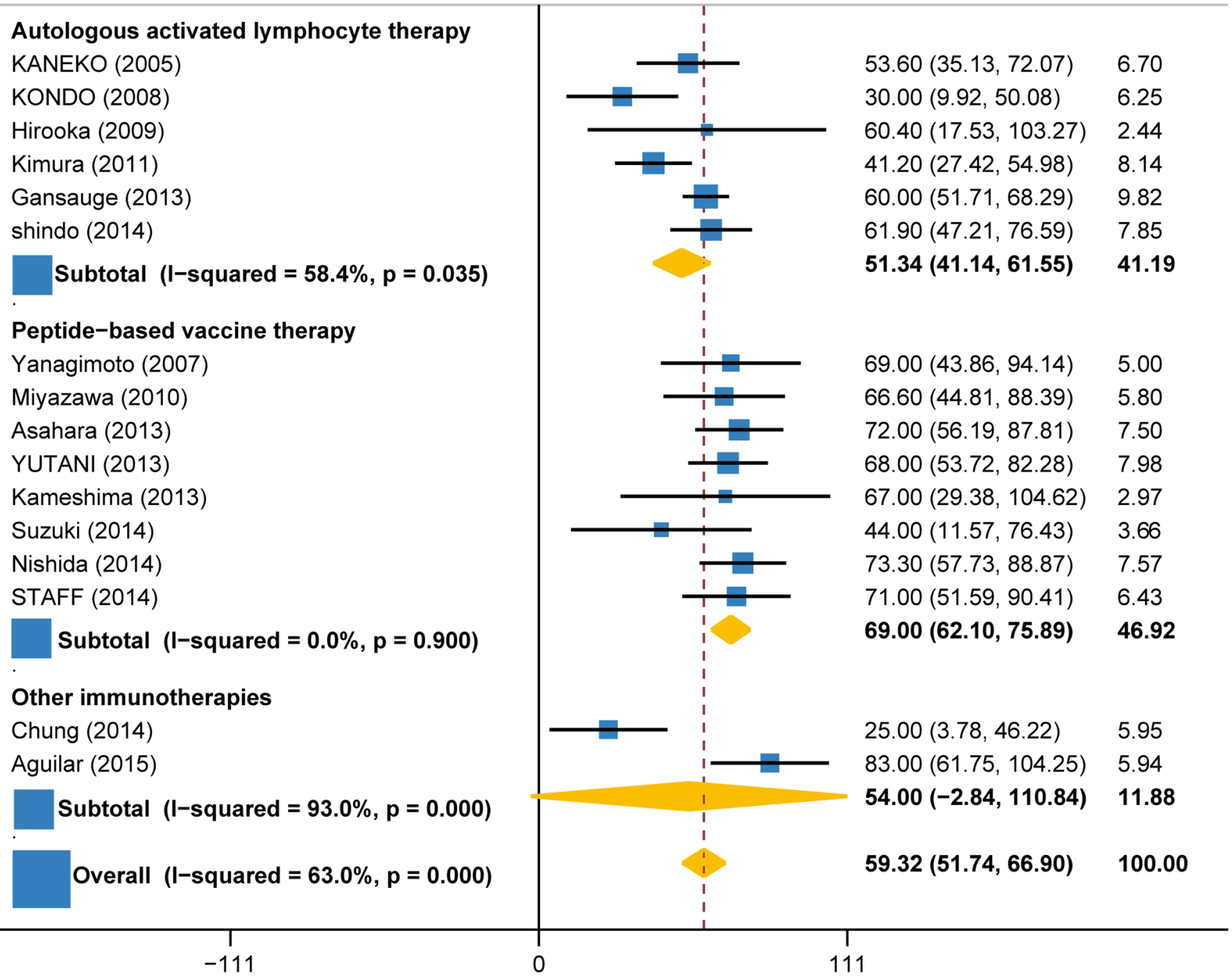

Figure 2: Disease control rate in trials of autologous activated lymphocyte therapy versus peptide-based vaccine therapy versus other therapy. 


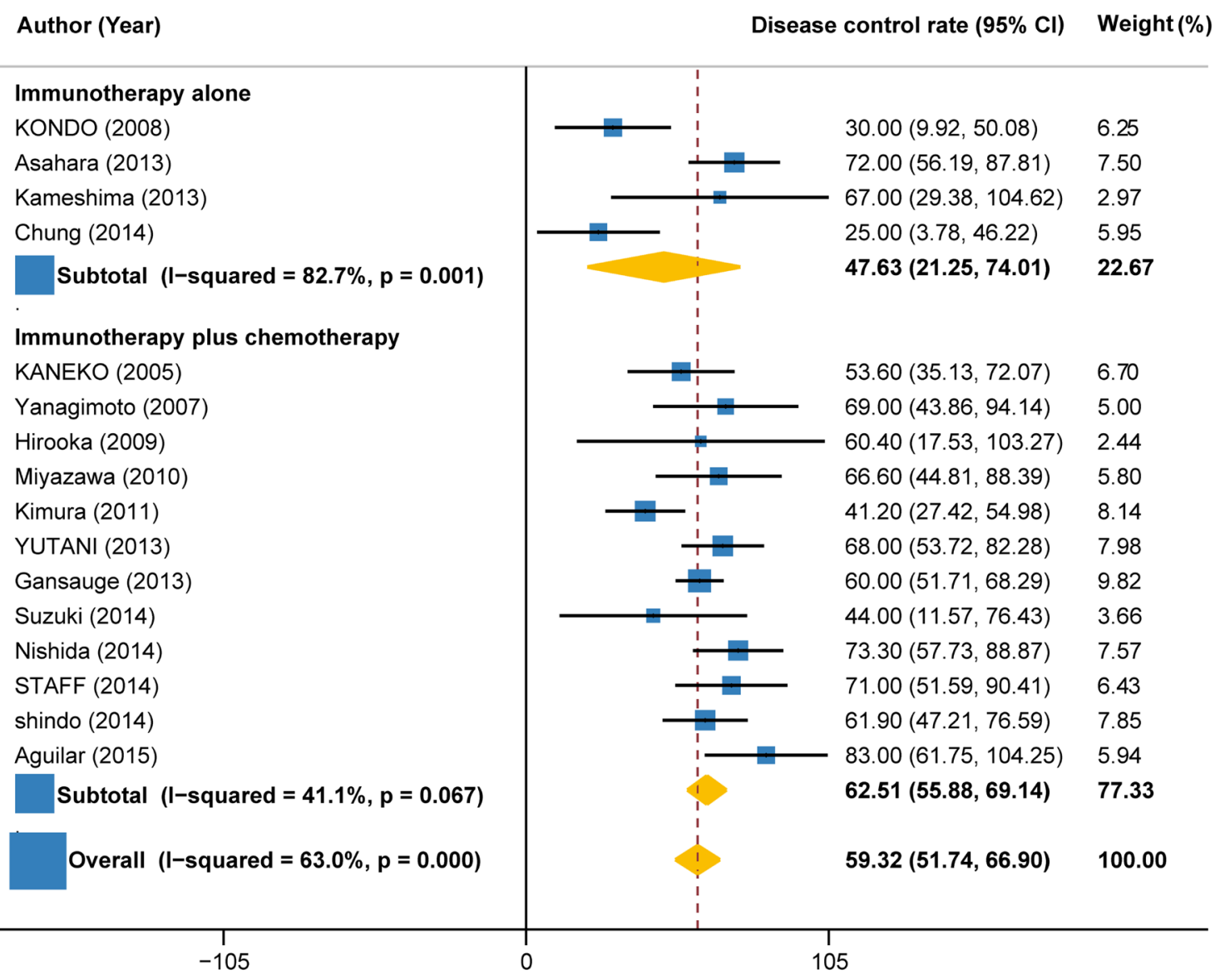

Figure 3: Disease control rate in trials of immunotherapy versus immunotherapy plus chemotherapy.

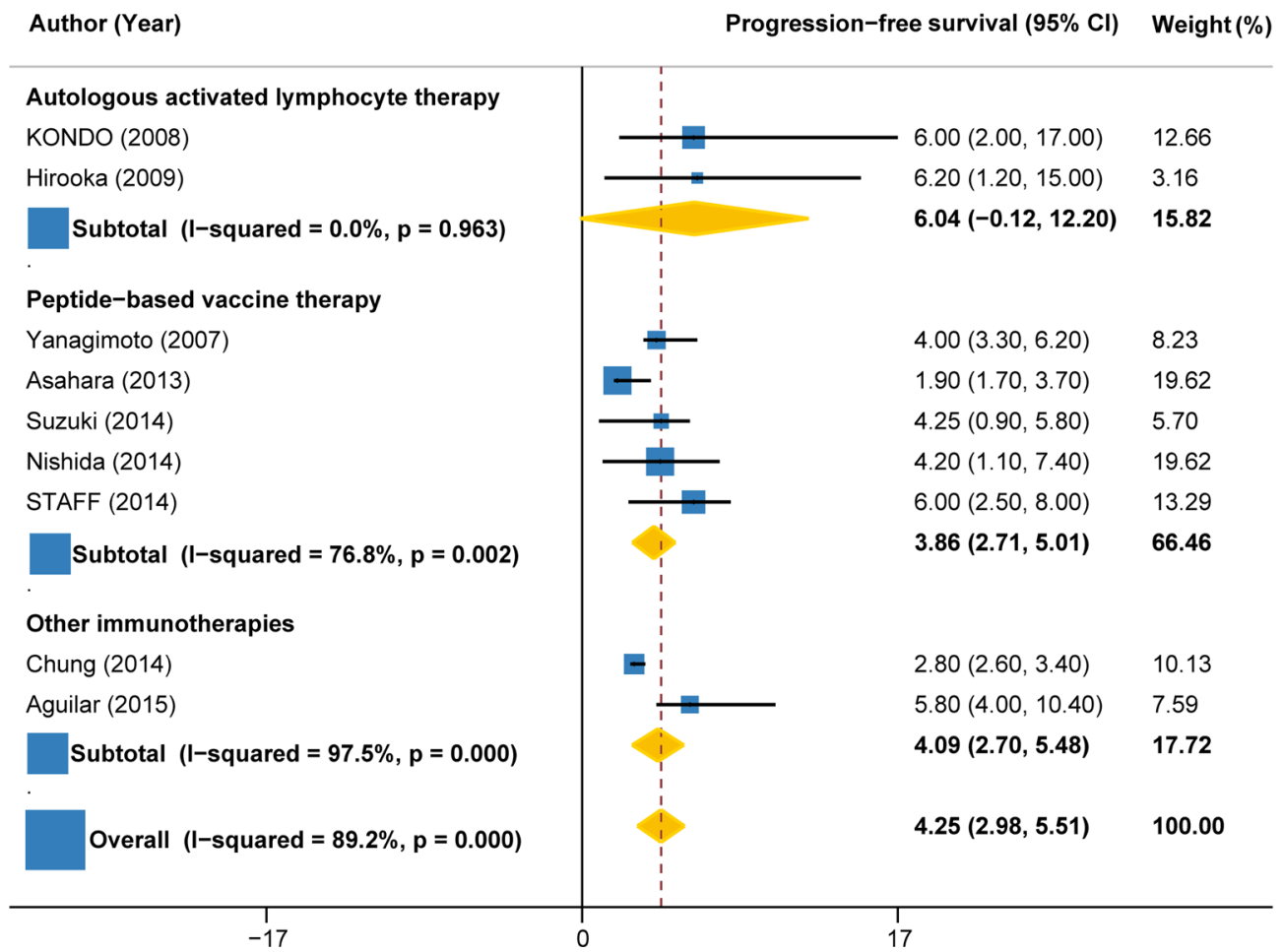

Figure 4: Progression-free survival in trials of autologous activated lymphocyte therapy versus peptide-based vaccine therapy versus other therapy. 


\section{Overall survival}

Overall survival data were available in 14 trials (327 patients), with values ranging from 3 months to 14.9 months. Overall, the pooled OS for immunotherapy was estimated as 7.90 months (95\%CI: 5.15 to 10.66 ), but with significant heterogeneity between individual trials $\left(\mathrm{I}^{2}=53.2 \%, P=0.010\right)$ (Figure 6). Subgroup analysis by the type of immunotherapy showed that the benefit was more significant for autologous activated lymphocyte therapy ( 8.28 months, $95 \% \mathrm{CI}$ : 0.91 to $15.65 ; \mathrm{I}^{2}=69.8 \%$, $P=0.010)$ compared with peptide-based vaccine therapy (7.40 months, $95 \%$ CI: 6.39 to $8.41 ; \mathrm{I}^{2}=69.5 \%, P=0.006$ ) (Figure 6). Subgroup analysis by the combination with or without chemotherapy demonstrated that the benefit was more significant for immunotherapy plus chemotherapy (8.67 months, $95 \%$ CI: 6.71 to $10.64 ; \mathrm{I}^{2}=61.4 \%, P=$ $0.004)$ as compared with immunotherapy alone (4.91 months, $95 \% \mathrm{CI}$ : -6.16 to $15.98 ; \mathrm{I}^{2}=0 \%, P=0.731$ ) (Figure 7).

\section{1-year survival rate}

1-year survival rate could be calculated from 14 trials (441 patients). The pooled 1-year survival rate for immunotherapy \pm chemotherapy was estimated as $30.12 \%$ (95\%CI: $21.60 \%$ to $38.64 \%$; $\mathrm{I}^{2}=75.4 \%, P<$ 0.001) (Figure 8). Subgroup analysis by the type of immunotherapy demonstrated that the 1-year survival rate for autologous activated lymphocyte therapy $(37.17 \%$, $95 \%$ CI: $22.23 \%$ to $52.11 \%$; $\left.\mathrm{I}^{2}=84.6 \%, P<0.001\right)$ was $88 \%$ higher than that of peptide-based vaccine therapy $\left(19.74 \%, 95 \%\right.$ CI: $12.19 \%$ to $27.29 \%$; $\mathrm{I}^{2}=26.6 \%, P=$ 0.235 ) (Figure 8). Subgroup analysis by the combination with or without chemotherapy showed that the 1-year survival rate for immunotherapy + chemotherapy $(32.32 \%$, $22.81 \%$ to $41.84 \%$; $\left.\mathrm{I}^{2}=74.4 \%, P<0.001\right)$ was about $51 \%$ higher than that of immunotherapy alone $(21.43 \%, 95 \% \mathrm{CI}$ : $5.08 \%$ to $37.79 \% ; \mathrm{I}^{2}=63.1 \%, P=0.067$ ) (Figure 9).

\section{Author (Year)}

Progression-free survival $(95 \% \mathrm{Cl})$

Weight (\%)

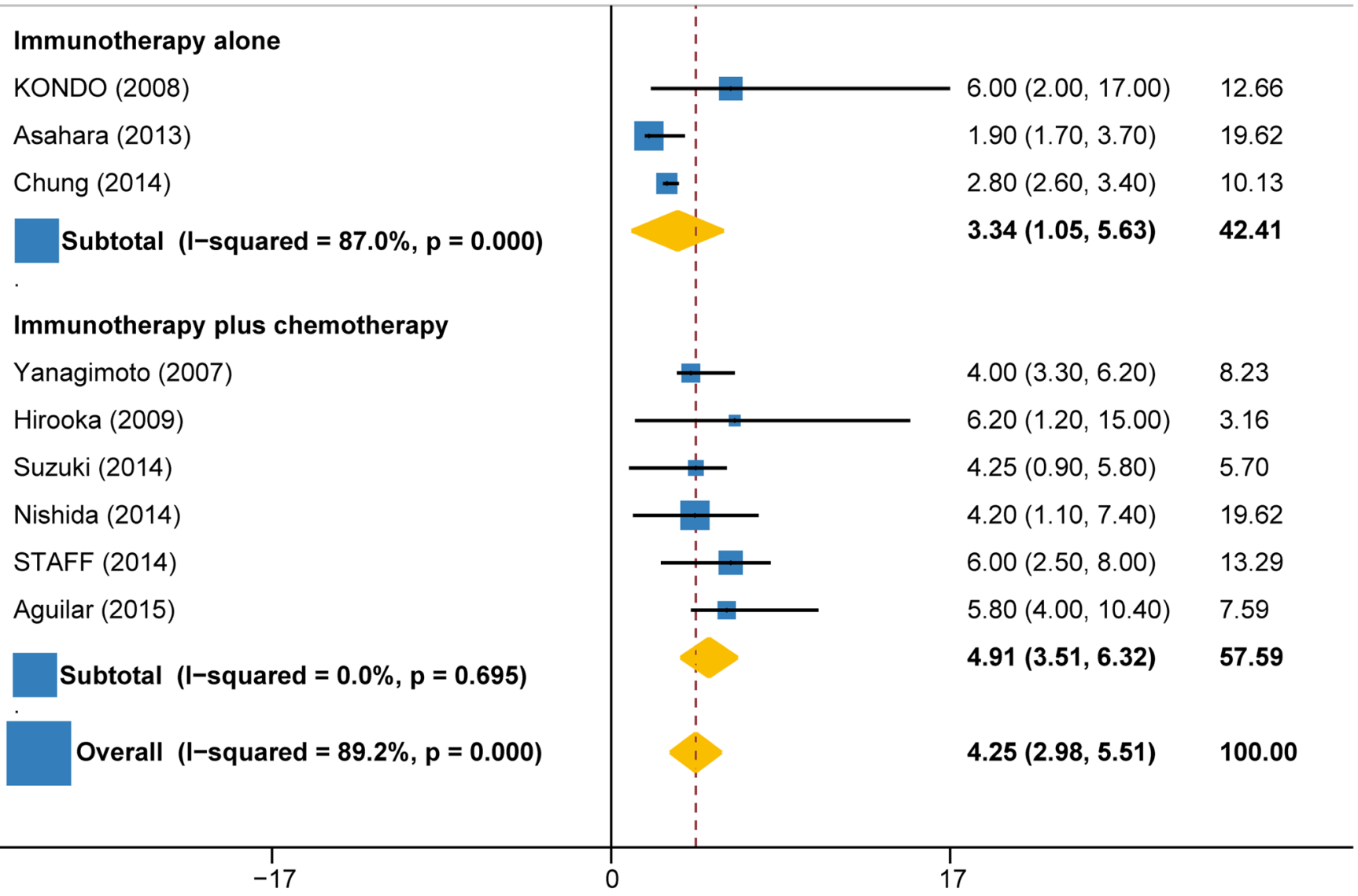

Figure 5: Progression-free survival in trials of immunotherapy versus immunotherapy plus chemotherapy. 


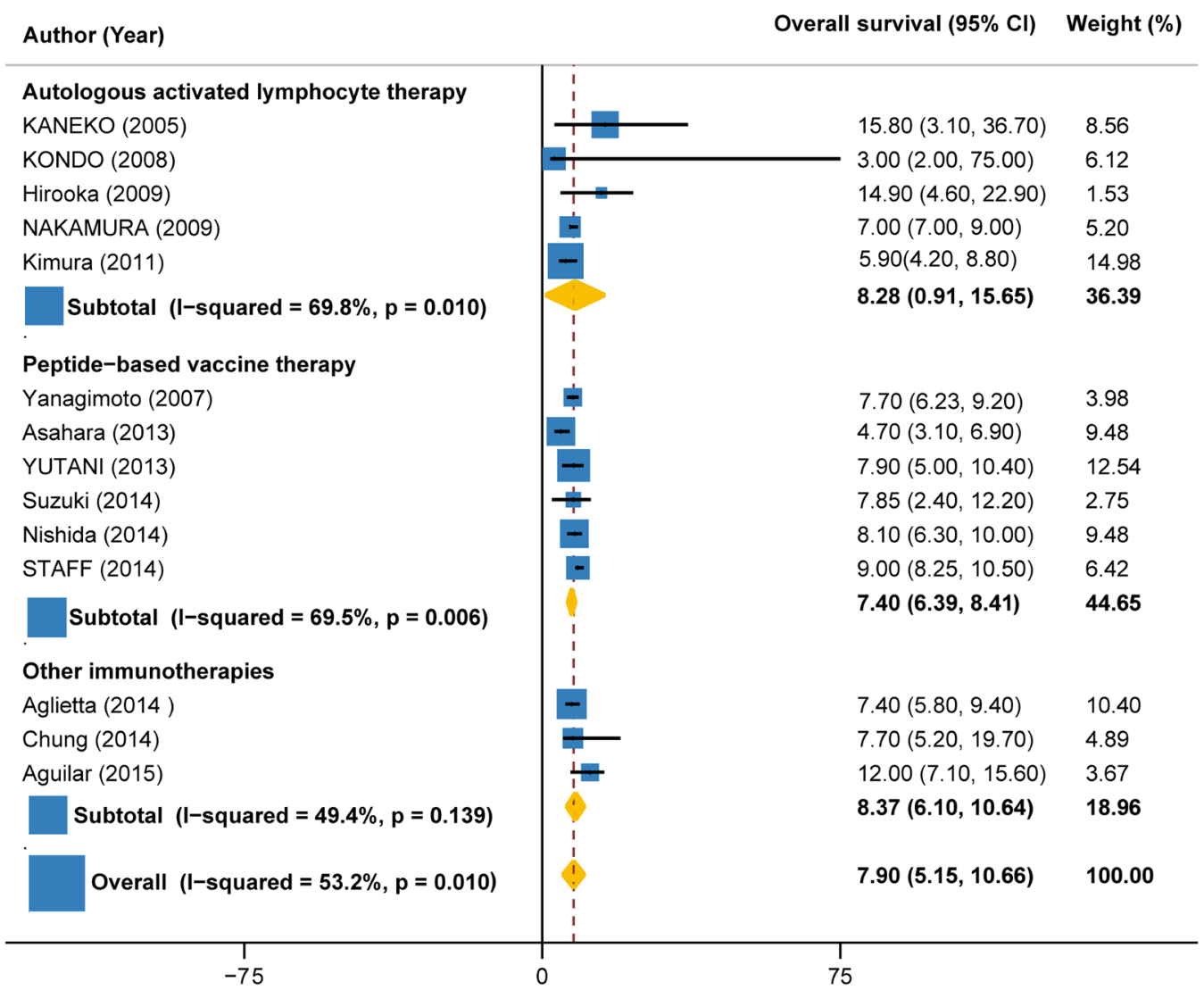

Figure 6: Overall survival in trials of autologous activated lymphocyte therapy versus peptide-based vaccine therapy versus other therapy.

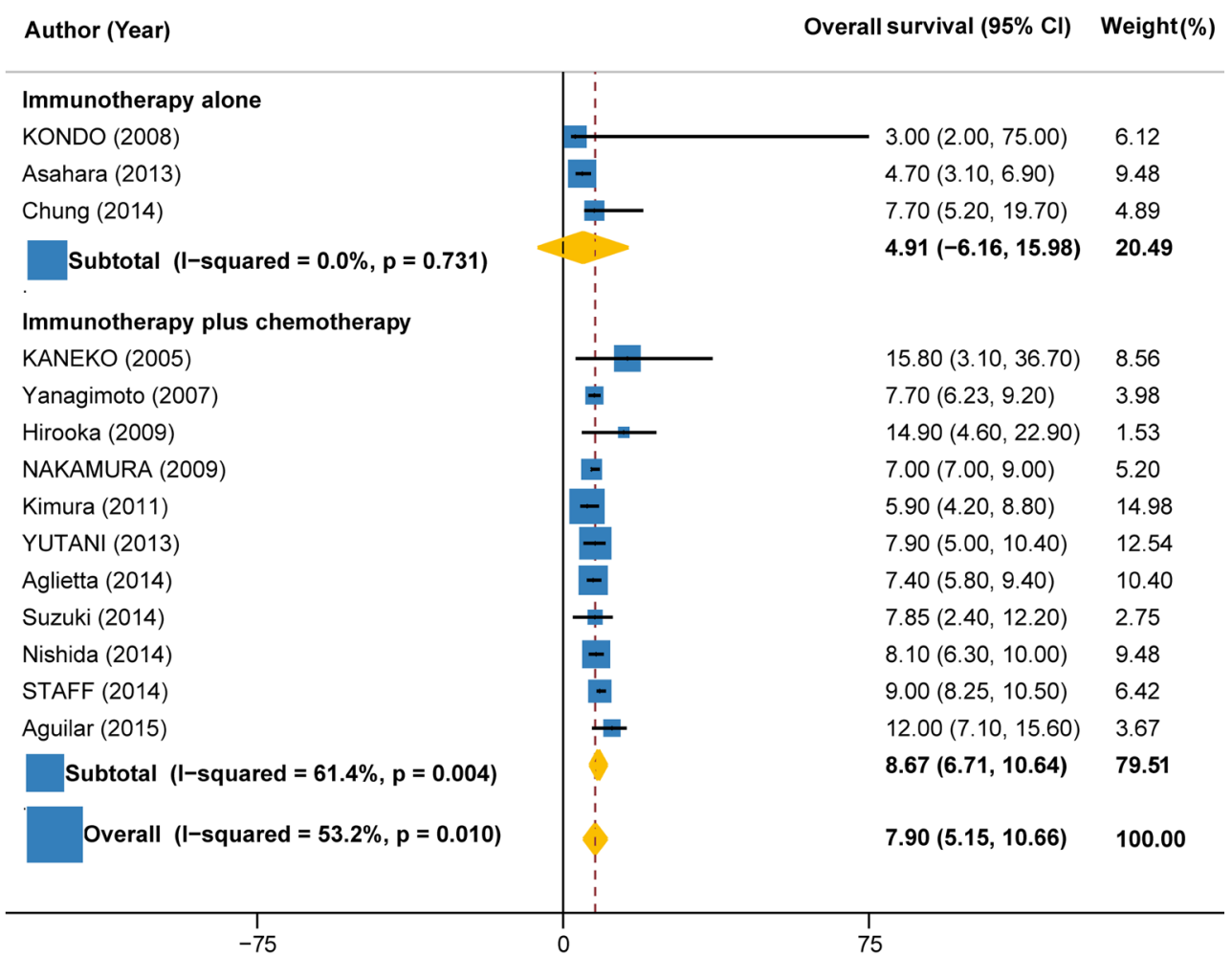

Figure 7: Overall survival in trials of immunotherapy versus immunotherapy plus chemotherapy. 


\section{Treatment-related adverse events}

Adverse events were monitored based on the National Institute Common Terminology Criteria for Adverse Events version 3.0. Reports on treatment-related adverse events (TRAEs) were variable among trials. Of the 18 trials, 9 trials ( 7 using autologous activated lymphocyte therapy \pm gemcitabine, 1 using peptide-based vaccine therapy, and 1 using monoclonal antibody + gemcitabine) reported no TRAEs, 7 trials (5 using peptidebased vaccine therapies, 1 using gene-mediated cytotoxic immunotherapy, and 1 using cytokine-induced killer cells) reported grade 3 TRAEs (e.g. anemia, lymphopenia, leukopenia, neutropenia, thrombocytopenia) with mean rate of $14.56 \%$ (ranging from $3.22 \%$ to $25.8 \%$ ) and no grade 4 TRAEs. The remaining 2 trials did not report TRAEs.

\section{Meta-regression analyses}

No variables met statistical significance on metaregression analyses $(P>0.05$ for all) (Tables 2-5).

\section{Publication bias}

Both the Egger's and Begg's tests revealed no publication bias for OS ( $P=0.951$ and 0.956 , respectively) and for PFS ( $P=0.085$ and 0.754 , respectively). Begg's test not Egger's test revealed no publication bias for 1-year survival rate ( $P=0.815$ and 0.000 , respectively). Both the Egger's and Begg's tests revealed publication bias for DCR ( $P=0.017$ and 0.000 , respectively).

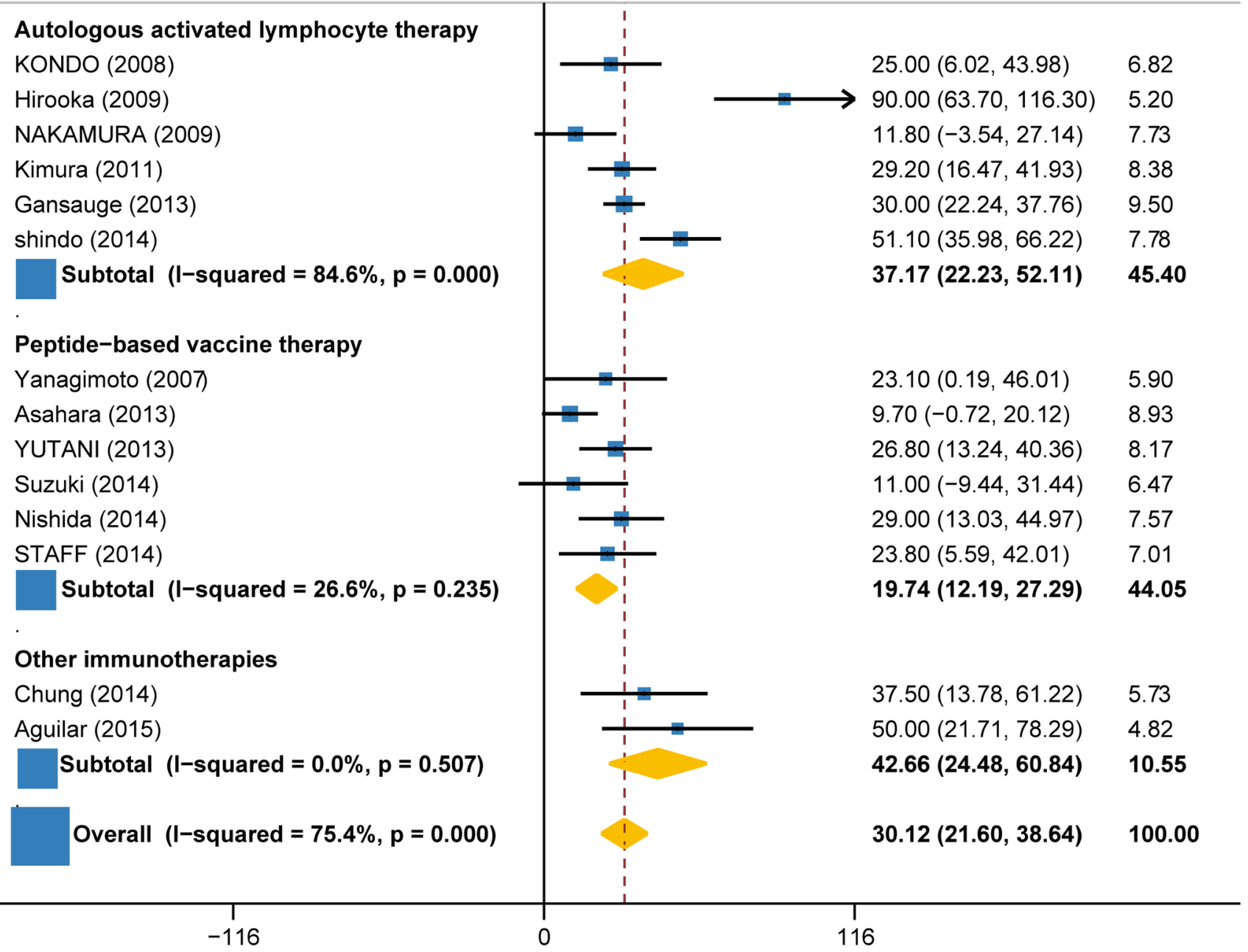

Figure 8: 1-year survival rate in trials of autologous activated lymphocyte therapy versus peptide-based vaccine therapy versus other therapy. 
Table 2: Univariate meta-regression analysis of possible sources of heterogeneity across the included trials reporting OS

\begin{tabular}{|l|c|c|c|}
\hline \multicolumn{1}{|c|}{ Possible source of heterogeneity } & Trials, $\mathbf{n}$ & Co-efficient (95\%CI) & P value \\
\hline Study design & 13 & $\begin{array}{c}\text { Phase I: }-2.10(-23.27,19.07) \\
\text { Phase I/II: -2 (-27.79, 23.79) }\end{array}$ & $\begin{array}{c}0.827 \\
0.865 \\
0.975\end{array}$ \\
\hline Number of patients & 14 & $-0.33(-23.85,23.19)$ & 0.941 \\
\hline Female/Male ratio & 13 & $0.027(-0.051,0.105)$ & 0.459 \\
\hline Publication year & 14 & $0.43(-094,1.79)$ & 0.509 \\
\hline Patients' age & 14 & $-0.396(-2.609,1.817)$ & 0.703 \\
\hline Type of immunotherapy & 14 & AALT: $-3.68(-15.67,8.31)$ & 0.513 \\
\hline Combination \pm chemotherapy & 14 & $4.12(-3.44,11.68)$ & 0.800 \\
\hline
\end{tabular}

Table 3: Univariate meta-regression analysis of possible sources of heterogeneity across the included trials reporting PFS

\begin{tabular}{|l|c|c|c|}
\hline \multicolumn{1}{|c|}{ Possible source of heterogeneity } & Trials, $\mathbf{n}$ & Co-efficient (95\%CI) & P value \\
\hline Study design & 8 & $\begin{array}{c}\text { Phase I: }-2.88(-18.72,12.96) \\
\text { Phase II: }-3.2(-20.22,13.82)\end{array}$ & $\begin{array}{l}0.660 \\
0.649\end{array}$ \\
\hline Number of patients & 9 & $-0.105(-0.420,0.209)$ & 0.453 \\
\hline Female/Male ratio & 8 & $-0.007(-0.038,0.527)$ & 0.710 \\
\hline Publication year & 9 & $-0.19(-1.43,1.06)$ & 0.732 \\
\hline Patients' age & 9 & $0.28(-1.27,1.83)$ & 0.686 \\
\hline Type of immunotherapy & 9 & AALT: $-2.73(-9.49,14.95)$ & 0.604 \\
\hline Combination \pm chemotherapy & 9 & PBVT: $-0.41(-7.52,6.70)$ & 0.892 \\
\hline
\end{tabular}

Table 4: Univariate meta-regression analysis of possible sources of heterogeneity across the included trials reporting DCR

\begin{tabular}{|l|c|c|c|}
\hline Possible source of heterogeneity & Trials, $\mathbf{n}$ & Co-efficient (95\%CI) & $\boldsymbol{P}$ value \\
\hline Study design & 14 & $\begin{array}{c}\text { Phase I: }-15.9(-180.4,148.6) \\
\text { Phase I/II: }-11(-218.1,196.1) \\
\text { Phase II: -34.1 (-87.2, 229.2) }\end{array}$ & $\begin{array}{c}0.834 \\
0.908 \\
0.654\end{array}$ \\
\hline Number of patients & 16 & $-0.156(-0.872,1.185)$ & 0.749 \\
\hline Female/Male ratio & 15 & $0.037(-0.333,0.407)$ & 0.832 \\
\hline Publication year & 16 & $-0.06(-0.907,8.95)$ & 0.989 \\
\hline Patients' age & 16 & $3.05(-8.84,14.93)$ & 0.591 \\
\hline Type of immunotherapy & 16 & AALT: $14.09(-551.53,79.7)$ & 0.650 \\
\hline Combination \pm chemotherapy & 16 & $-23.9(-76.5,28.7)$ & 0.361 \\
\hline
\end{tabular}


Table 5: Univariate meta-regression analysis of possible sources of heterogeneity across the included trials reporting 1-year survival rate

\begin{tabular}{|l|l|l|l|}
\hline Possible source of heterogeneity & Trials, $\mathbf{n}$ & Co-efficient $(\mathbf{9 5} \% \mathbf{C I})$ & $\boldsymbol{P}$ value \\
\hline Study design & 13 & $\begin{array}{l}\text { Phase I: }-9.55(-65.36,46.27) \\
\text { Phase I/II: }-9.56(-68.86,49.73) \\
\text { Phase II: 9.80 (-60.6, 80.21) }\end{array}$ & $\begin{array}{l}0.708 \\
0.724 \\
0.760\end{array}$ \\
\hline Number of patients & 14 & $0.131(-0.38,0.65)$ & 0.590 \\
\hline Female/Male ratio & 14 & $-0.003(-0.311,0.65)$ & 0.590 \\
\hline Publication year & 14 & $-0.189(-4.99,4.62)$ & 0.913 \\
\hline Patients' age & 14 & $-0.322(-6.939,6.296)$ & 0.917 \\
\hline Type of immunotherapy & 14 & $\begin{array}{l}\text { AALT: }-22.73(-91.86,46.40) \\
\text { PBVT: }-28.02(-95.49,39.46)\end{array}$ & 0.484 \\
\hline Combination \pm chemotherapy & 14 & $5.02(-18.59,28.64)$ & 0.650 \\
\hline
\end{tabular}

\section{DISCUSSION}

The present meta-analysis gathers all currently available data from single-arm studies reporting immunotherapy for those patients with advanced pancreatic cancer. To our best of knowledge, ours is the first meta-analysis to analyze the efficacy and safety of immunotherapy using single-arm trials. The results showed immunotherapy is more effective than other previously reported standard treatmentin terms of OS, PFS, 1-year survival rate for advanced pancreatic carcinoma [28-32]. After stratifying trials according to the type of immunotherapy, we found that the benefits of autologous activated lymphocyte therapy were more

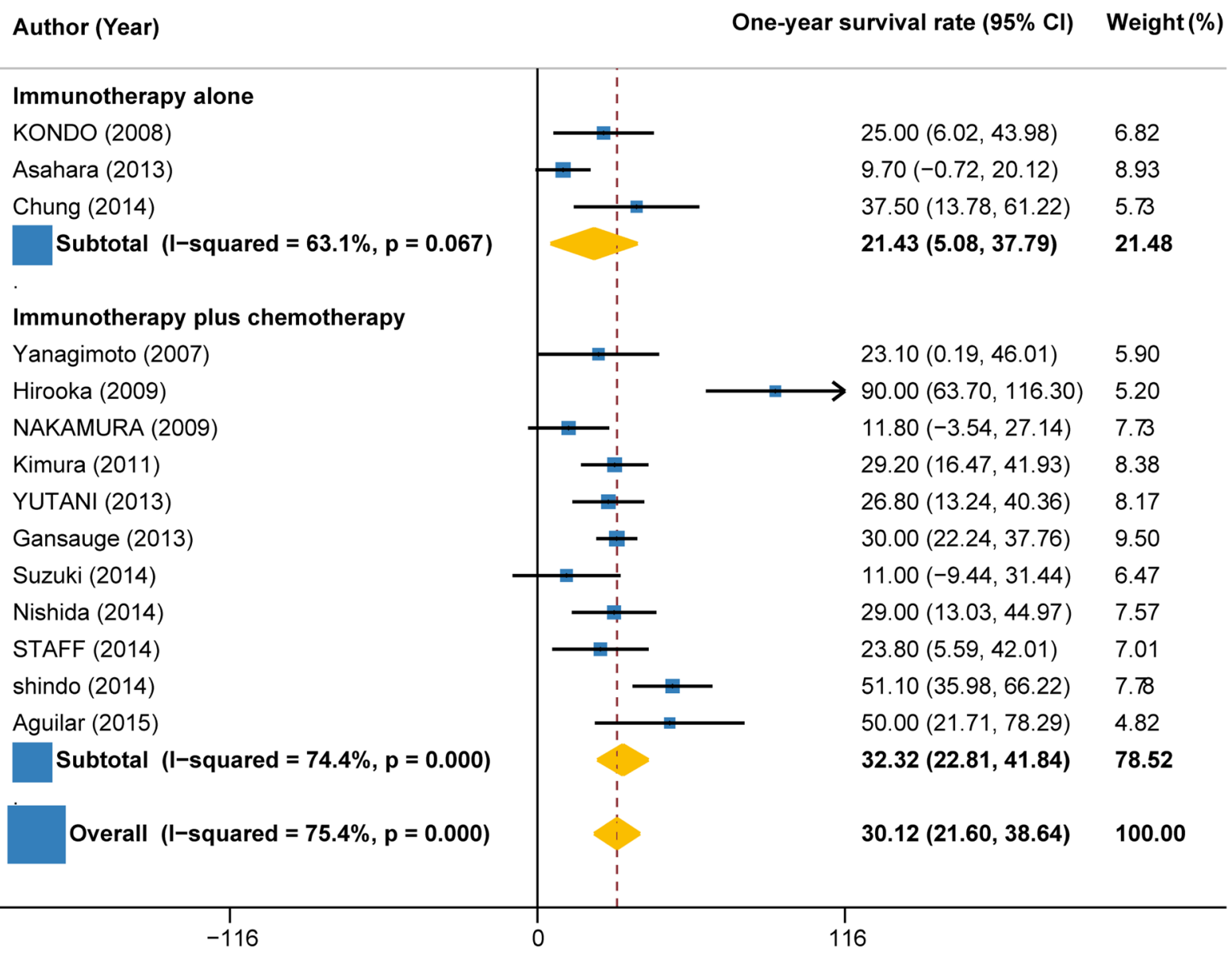

Figure 9: 1-year survival rate in trials of immunotherapy versus immunotherapy plus chemotherapy. 
significant than that of peptide-based vaccine therapy (OS: 8.28 months vs. 7.40 months; PFS: 6.04 months vs. 3.86 months; 1 -year survival rate: $37.17 \%$ vs. $19.74 \%$ ). Since the early $1990 \mathrm{~s}$, many institutions have actively studied the use of autologous activated lymphocyte therapies, including lymphokine-activated killer lymphocytes (LAK), cytotoxic T-lymphocyte (CTL), and dendritic cell (DC) [33]. Among various immune cell types studied as potential candidates for effective immunotherapy, DCs are potent antigen-presenting cells that participate in the initiation of T-cell immunity and involved in the regulation of both innate and adoptive immune response [24, 34]. Some previous clinical trials have used the combination antigen-pulsed or peptide-pulsed DC vaccine with LAK cells or CTLs in patients with advanced pancreatic cancer and observed significantly prolonged survival time [10, 20, 21, 23, 24].

As a matter of fact, all trials performed so far comparing immunotherapy with standard therapies failed to show the superiority of the former [35]. Obviously, cancer immunotherapy would not be able to take the place of chemotherapy and radiotherapy. Moreover, though recent clinical trials have investigated the sequential administration of immunotherapy and chemo (radio) therapy, the immunosuppressive effects of these standard therapies may weaken the efficacy of immunotherapy. Therefore, it will be essential to find an optimal way to integrate immunotherapy with chemo(radio) therapy. Subgroup analysis indicated that the benefits of combined therapy were more significant than that of immunotherapy alone (DCR: $62.51 \%$ vs. $47.63 \%$; OS: 8.67 months vs. 4.91 months; PFS: 4.91 months vs. 3.34 months; 1-year survival rate: $32.32 \%$ vs. $21.43 \%$ ). For chemotherapy, gemcitabine is currently one of the standard therapies for advanced pancreatic cancer, although many chemotherapeutic drugs have been used in clinical trials over the past two decades [35]. However, the effect of gemcitabine is limited and most patients received gemcitabine die within 6 months. Interestingly, some recent reports showed that gemcitabine may improve patients' response to immunotherapy [22]. Dauer et al have demonstrated in their in vitro study that human pancreatic cancer cell lines could be sensitized by gemcitabine against CTL-mediated lysis [36]. DC vaccine plus gemcitabine prolongs survival time in a animal model [37]. Although some trials of combined therapies including not only gemcitabine but also other cytotoxic drugs showed improved response rates compared with gemcitabine alone, they failed to gain survival benefits [38-41]. Thus, most trials included in this meta-analysis combined only gemcitabine with immunotherapy.

The importance of treatment-related adverse events (TRAEs) that related to immunotherapy must be emphasized. Reporting on TRAEs was variable across trials. Of the included 18 trials, no trails observed related to autologous activated lymphocyte therapy. Five trials using peptide-based vaccine therapies reported (16.6 $\pm 3.9) \%$ grade III TRAEs and no grade IV TRAEs and one trial reported no TRAEs. Therefore, immunotherapy used in advanced pancreatic cancer patients is safe and no evidence of autoimmune disease was noted, especially for autologous activated lymphocyte therapy.

In summary, cancer immunotherapy was well tolerated and effective in the treatment of advanced pancreatic carcinoma. Currently, available clinical evidences suggest that the combination immunotherapy with standard therapies should be recommended as preferred therapy for those patients with advanced pancreatic carcinoma. For vaccine-based immunotherapy, autologous activated lymphocyte therapy was considered to be the more promising and encouraging treatment compared with peptide-based vaccine therapy. Further clinical investigations, especially randomized controlled trials are warranted to determine the effectiveness and tolerability of immunotherapy.

\section{MATERIALS AND METHODS}

\section{Trials identification}

We conducted separate PubMed (inception to June 2016), EMBASE (inception to June 2016) and the Cochrane Library (inception to June 2016) searches of all relevant English language articles using an extension of the Cochrane search strategy [25]. Potential studies were identified by using the following keywords: "immunotherapy" OR "immunotherapeutic" OR "immune-cell based cancer therapy" OR "vaccinebased immunotherapy" AND "pancreatic cancer" OR "pancreatic carcinoma" OR "pancreatic adenocarcinoma" AND "advanced" OR "unresectable" OR "metastatic" OR "refractory" OR "inoperable". Further information was manually searched reference lists from already retrieved studies and general medical journals (e.g., New England Journal of Medicine, The Lancet, British Journal of Medicine and JAMA) and journals in the cancer field (e.g., Journal of Clinical Oncology, Cancer Research, Cancer, Annals of Oncology, British Journal of Cancer, and Cancer Treatment Reviews). In particular, review articles were also examined for published results. By carefully checking the body of each publication and the name of all authors, we avoided duplications of data. The search strategy used is illustrated in Figure 1.

\section{Selection criteria}

The selection criteria was as follows: (1) Trials were in the English language and were limited to human trials; (2) Prospective or retrospective clinical trials with or without a control population were eligible for inclusion; (3) Trials assessed the efficacy and safety 
of immunotherapy in the treatment of APC. (4) Trials reported endpoints without $95 \% \mathrm{CI}$ or mean survival time were not included.

\section{Primary and secondary endpoints}

Data on disease control rate (DCR) (partial response $[\mathrm{PR}]+$ complete response $[\mathrm{CR}]+$ stable disease $[\mathrm{SD}])$, overall survival (OS), progression-free survival (PFS), 1-year survival rate and treatment-related adverse events (TRAEs) were independently extracted by two reviewer, with any discrepancies resolved by consensus (and if necessary with a third reviewer). The primary endpoint evaluated was DCR. The secondary endpoints evaluated were OS, PFS, 1-year survival rate and TRAEs. OS and PFS were estimated from the date of the initial treatment to the date of death or final follow-up and the date of disease progression, respectively. These endpoints were analyzed for all included studies for which data were available. The subgroup analyses were conducted according to the type of immunotherapy (autologous activated lymphocyte therapies, peptide vaccine therapy, and other immunotherapies such as monoclonal antibodies), combination with or without chemotherapy.

\section{Statistical analysis}

We performed bootstrapping (number of samples $=1000)$ to calculate the $95 \%$ CI for OS, PFS, DCR and 1-year survival rate if study didn't report these endpoints' 95\% CIs but reported individual participant data. In particular, we used metaprop command (metaprop DCR [or 1-year survival rate], random second (fixed) $\mathrm{ftt}$ cimethod (exect) label (namevar = Author, yearvar $=$ Year) to summarize DCR and 1-year survival rate. Considering the heterogeneity across studies, metaanalysis was performed using a random-effects model, using the DerSimonian-Laird method [26]. Heterogeneity across studies was assessed using the Cochran's Q and ${ }^{2}$ statistic with values ranging from $0 \%$ (no heterogeneity) to $100 \%$; values $>50 \%$ indicated significant heterogeneity [27]. Univariate meta-regression using REML method was performed to find out sources of heterogeneity including study design, mean age, female/male (F/M) ratio, number of patients, publication year, the type of immunotherapy, and combination with or without chemotherapy. Additionally, pre-specified subgroup analyses were performed (i) by type of immunotherapy; (ii) by combination with or without chemotherapy. Publication bias was examined utilizing funnel plots by the Begg's and Egger's methods. All data were recorded in a Microsoft Excel spreadsheet (Microsoft Corp, Redmond, WA) and analyzed using Statistical Package for Social Sciences (SPSS) software version 23.0 (SPSS Inc., Chicago, IL, USA) and STATA 12.0 (Stata Corp LP, College Station,
Texas, USA).

\section{Abbreviations}

APC Advanced pancreatic cancer

DCR Disease control rate

OS Overall survival

PFS Progression-free survival

TRAEs Treatment-related adverse events

AALT Autologous activated lymphocyte therapy

PBVT peptide-based vaccine therapy

\section{CONFLICTS OF INTEREST}

The authors have declared that no conflict of interest exists.

\section{FUNDING}

This manuscript is supported by funding from the National Scientific Foundation of China (81571664) and the Science and Technology Planning Project of Guangdong Province (2014A020212244).

\section{Author contributions}

Bin Zhang, Yuhao Dong designed and supervised the study. Shuixing Zhang obtained funding. Bin Zhang, Yuhao Dong, Jing Liu, and Zhouyang Lian searched and selected the trials. Long Liang, Wenbo Chen, and Lu Zhang participated in data collection and checking. Bin Zhang, Xiaoning Luo, Shufang Pei, Xiaokai Mo, Wenhui Huang, Fusheng Ouyang, and Baoliang Guo did the statistical analyses. Bin Zhang wrote the draft, with the revisions from the other investigators, All authors had full access to all the data and had final responsibility for the decision to submit for publication.

\section{REFERENCES}

1. Cappello P, Rolla S, Chiarle R, Principe M, Cavallo F, Perconti G, Feo S, Giovarelli M and Novelli F. Vaccination with ENO1 DNA prolongs survival of genetically engineered mice with pancreatic cancer. Gastroenterology. 2013;144:1098-1106.

2. Brunet LR, Hagemann T, Andrew G, Mudan S, and Marabelle A. Have lessons from past failures brought us closer to the success of immunotherapy in metastatic pancreatic cancer? Oncoimmunology. 2016;5:e1112942.

3. Seufferlein T, Bachet JB, Van Cutsem E and Rougier P. Pancreatic adenocarcinoma: ESMO-ESDO Clinical Practice Guidelines for diagnosis, treatment and follow-up. Ann Oncol 2012;23 Suppl 7:i33-i40.

4. Aguilar LK, Shirley LA, Chung VM, Marsh CL, Walker J, 
Coyle W, Marx H, Bekaii-Saab T, Lesinski GB, Swanson B, Sanchez D, Manzanera AG, Aguilar-Cordova E, et al. Gene-mediated cytotoxic immunotherapy as adjuvant to surgery or chemoradiation for pancreatic adenocarcinoma. Cancer Immunol Immunother. 2015;64:727-736.

5. Seufferlein T, Bachet JB, Van Cutsem E, and Rougier P. Pancreatic adenocarcinoma: ESMO-ESDO Clinical Practice Guidelines for diagnosis, treatment and follow-up. Ann Oncol. 2012;23 Suppl 7:i33-i40.

6. Suzuki N, Hazama S, Ueno T, Matsui H, Shindo Y, Iida M, Yoshimura K, Yoshino S, Takeda K and Oka M. A phase I clinical trial of vaccination with KIF20A-derived peptide in combination with gemcitabine for patients with advanced pancreatic cancer. J Immunother. 2014;37:36-42.

7. Nishida S, Koido S, Takeda Y, Homma S, Komita H, Takahara A, Morita S, Ito T, Morimoto S, Hara K, Tsuboi A, Oka Y, Yanagisawa S, et al. Wilms tumor gene (WT1) peptide-based cancer vaccine combined with gemcitabine for patients with advanced pancreatic cancer. J Immunother. 2014;37:105-114.

8. Chung MJ, Park JY, Bang S, Park SW and Song SY. Phase II clinical trial of ex vivo-expanded cytokine-induced killer cells therapy in advanced pancreatic cancer. Cancer Immunol Immunother. 2014;63:939-946.

9. Niu L, Chen J, He L, Liao M, Yuan Y, Zeng J, Li J, Zuo $\mathrm{J}$ and $\mathrm{Xu} \mathrm{K}$. Combination treatment with comprehensive cryoablation and immunotherapy in metastatic pancreatic cancer. Pancreas. 2013;42:1143-1149.

10. Kondo H, Hazama S, Kawaoka T, Yoshino S, Yoshida S, Tokuno K, Takashima M, Ueno T, Hinoda Y and Oka M. Adoptive immunotherapy for pancreatic cancer using MUC1 peptide-pulsed dendritic cells and activated T lymphocytes. Anticancer Res. 2008;28:379-387.

11. Aglietta M, Barone C, Sawyer MB, Moore MJ, Miller WJ, Bagala C, Colombi F, Cagnazzo C, Gioeni L, Wang E, Huang B, Fly KD and Leone F. A phase I dose escalation trial of tremelimumab (CP-675,206) in combination with gemcitabine in chemotherapy-naive patients with metastatic pancreatic cancer. Ann Oncol. 2014; 25: 1750-1755.

12. Hersh EM, Metch BS, Muggia FM, Brown TD, Whitehead RP, Budd GT, Rinehart JJ, Crawford ED, Bonnet JD and Behrens BC. Phase II studies of recombinant human tumor necrosis factor alpha in patients with malignant disease: A summary of the Southwest Oncology Group experience. J Immunother (1991). 1991;10:426-431.

13. Yamamoto K, Mine T, Katagiri K, Suzuki N, Kawaoka T, Ueno T, Matsueda S, Yamada A, Itoh K, Yamana H and Oka M. Immunological evaluation of personalized peptide vaccination for patients with pancreatic cancer. Oncol Rep. 2005;13:874-883.

14. Yutani S, Komatsu N, Yoshitomi M, Matsueda S, Yonemoto K, Mine T, Noguchi M, Ishihara Y, Yamada A, Itoh $\mathrm{K}$ and Sasada T. A phase II study of a personalized peptide vaccination for chemotherapy-resistant advanced pancreatic cancer patients. Oncol Rep. 2013;30:1094-1100.
15. Staff C, Mozaffari F, Frodin JE, Mellstedt H and Liljefors M. Telomerase (GV1001) vaccination together with gemcitabine in advanced pancreatic cancer patients. Int $\mathrm{J}$ Oncol. 2014;45:1293-1303.

16. Nishida S, Koido S, Takeda Y, Homma S, Komita H, Takahara A, Morita S, Ito T, Morimoto S, Hara K, Tsuboi A, Oka Y, Yanagisawa S, et al. Wilms tumor gene (WT1) peptide-based cancer vaccine combined with gemcitabine for patients with advanced pancreatic cancer. J Immunother. 2014;37:105-114.

17. Miyazawa M, Ohsawa R, Tsunoda T, Hirono S, Kawai M, Tani M, Nakamura Y and Yamaue H. Phase I clinical trial using peptide vaccine for human vascular endothelial growth factor receptor 2 in combination with gemcitabine for patients with advanced pancreatic cancer. Cancer Sci. 2010;101:433-439.

18. Asahara S, Takeda K, Yamao K, Maguchi H and Yamaue H. Phase I/II clinical trial using HLA-A24-restricted peptide vaccine derived from KIF20A for patients with advanced pancreatic cancer. J Transl Med. 2013;11:291.

19. Petersen TR, Dickgreber $\mathrm{N}$ and Hermans IF. Tumor antigen presentation by dendritic cells. Crit Rev Immunol. 2010;30:345-386.

20. Shindo Y, Hazama S, Maeda Y, Matsui H, Iida M, Suzuki N, Yoshimura K, Ueno T, Yoshino S, Sakai K, Suehiro Y, Yamasaki T, Hinoda Y, et al. Adoptive immunotherapy with MUC1-mRNA transfected dendritic cells and cytotoxic lymphocytes plus gemcitabine for unresectable pancreatic cancer. J Transl Med. 2014; 12:175.

21. Hirooka Y, Itoh A, Kawashima H, Hara K, Nonogaki K, Kasugai T, Ohno E, Ishikawa T, Matsubara H, Ishigami M, Katano Y, Ohmiya N, Niwa Y, et al. A combination therapy of gemcitabine with immunotherapy for patients with inoperable locally advanced pancreatic cancer. Pancreas. 2009;38:e69-e74.

22. Kimura Y, Tsukada J, Tomoda T, Takahashi H, Imai K, Shimamura K, Sunamura M, Yonemitsu Y, Shimodaira S, Koido S, Homma S and Okamoto M. Clinical and immunologic evaluation of dendritic cell-based immunotherapy in combination with gemcitabine and/ or S-1 in patients with advanced pancreatic carcinoma. Pancreas. 2012;41:195-205.

23. Kaneko T, Goto S, Kato A, Akeyama A, Tomonaga M, Fujimoto K, Miyamoto Y, Eriguchi $\mathrm{M}$ and Egawa K. Efficacy of immuno-cell therapy in patients with advanced pancreatic cancer. Anticancer Res. 2005;25:3709-3714.

24 Nakamura M, Wada J, Suzuki H, Tanaka M, Katano M and Morisaki T. Long-term outcome of immunotherapy for patients with refractory pancreatic cancer. Anticancer Res. 2009;29:831-836.

25. Dickersin K, Scherer R and Lefebvre C. Identifying relevant studies for systematic reviews. BMJ. 1994;309:1286-1291.

26. DerSimonian R, Laird N. Meta-analysis in clinical trials. Control Clin Trials. 1986;7:177-188. 
27. Shelton E, Laharie D, Scott FI, Mamtani R, Lewis JD, Colombel JF and Ananthakrishnan AN. Cancer recurrence following Immune-Suppressive therapies in patients with Immune-Mediated diseases: A systematic review and metaanalysis. Gastroenterology. 2016

28. Boeck S, Weigang-Kohler K, Fuchs M, Kettner E, Quietzsch D, Trojan J, Stotzer O, Zeuzem S, Lordick F, Kohne CH, Kroning H, Steinmetz T, Depenbrock H, et al. Second-line chemotherapy with pemetrexed after gemcitabine failure in patients with advanced pancreatic cancer: A multicenter phase II trial. Ann Oncol. 2007;18:745-751.

29. Kulke MH, Blaszkowsky LS, Ryan DP, Clark JW, Meyerhardt JA, Zhu AX, Enzinger PC, Kwak EL, Muzikansky A, Lawrence C and Fuchs CS. Capecitabine plus erlotinib in gemcitabine-refractory advanced pancreatic cancer. J Clin Oncol. 2007;25: 4787-4792.

30. Oh SY, Kim HJ, Kim TH, Lee GW, Kim HG, Jeong CY, Kwon HC and Kang JH. Pilot study of irinotecan/ oxalipltin (IROX) combination chemotherapy for patients with gemcitabine- and 5-fluorouracil- refractory pancreatic cancer. Invest New Drugs. 2010; 28:343-349.

31. O'Reilly EM, Niedzwiecki D, Hall M, Hollis D, BekaiiSaab T, Pluard T, Douglas K, Abou-Alfa GK, Kindler HL, Schilsky RL and Goldberg RM. A Cancer and Leukemia Group B phase II study of sunitinib malate in patients with previously treated metastatic pancreatic adenocarcinoma (CALGB 80603). Oncologist. 2010;15:1310-1319.

32. Ko AH, Tempero MA, Shan YS, Su WC, Lin YL, Dito E, Ong A, Wang YW, Yeh CG and Chen LT. A multinational phase 2 study of nanoliposomal irinotecan sucrosofate (PEP02, MM-398) for patients with gemcitabine-refractory metastatic pancreatic cancer. Br J Cancer. 2013;109:920925 .

33. Egawa K. Immuno-cell therapy of cancer in Japan. Anticancer Res. 2004; 24: 3321-3326.

34. Karakhanova S, Mosl B, Harig S, von Ahn K, Fritz J, Schmidt J, Jager D, Werner J and Bazhin AV. Influence of interferon-alpha combined with chemo (radio) therapy on immunological parameters in pancreatic adenocarcinoma. Int J Mol Sci. 2014;15: 4104-4125.
35. Salman B, Zhou D, Jaffee EM, Edil BH and Zheng L. Vaccine therapy for pancreatic cancer. Oncoimmunology. 2013;2:e26662.

36. Dauer M, Herten J, Bauer C, Renner F, Schad K, Schnurr $\mathrm{M}$, Endres $\mathrm{S}$ and Eigler A. Chemosensitization of pancreatic carcinoma cells to enhance $\mathrm{T}$ cell-mediated cytotoxicity induced by tumor lysate-pulsed dendritic cells. J Immunother. 2005;28: 332-342.

37. Bauer C, Bauernfeind F, Sterzik A, Orban M, Schnurr M, Lehr HA, Endres S, Eigler A and Dauer M. Dendritic cellbased vaccination combined with gemcitabine increases survival in a murine pancreatic carcinoma model. Gut. 2007;56:1275-1282.

38. Louvet C, Labianca R, Hammel P, Lledo G, Zampino MG, Andre T, Zaniboni A, Ducreux M, Aitini E, Taieb J, Faroux R, Lepere C and de Gramont A. Gemcitabine in combination with oxaliplatin compared with gemcitabine alone in locally advanced or metastatic pancreatic cancer: Results of a GERCOR and GISCAD phase III trial. J Clin Oncol. 2005;23:3509-3516.

39. Philip PA, Benedetti J, Corless CL, Wong R, O'Reilly EM, Flynn PJ, Rowland KM, Atkins JN, Mirtsching BC, Rivkin SE, Khorana AA, Goldman B, Fenoglio-Preiser CM, et al. Phase III study comparing gemcitabine plus cetuximab versus gemcitabine in patients with advanced pancreatic adenocarcinoma: Southwest Oncology Group-directed intergroup trial S0205. J Clin Oncol. 2010;28:3605-3610.

40. Ueno H, Ioka T, Ikeda M, Ohkawa S, Yanagimoto H, Boku N, Fukutomi A, Sugimori K, Baba H, Yamao K, Shimamura T, Sho M, Kitano M, et al. Randomized phase III study of gemcitabine plus S-1, S-1 alone, or gemcitabine alone in patients with locally advanced and metastatic pancreatic cancer in Japan and Taiwan: GEST study. J Clin Oncol. 2013;31:1640-1648.

41. Berlin JD, Catalano P, Thomas JP, Kugler JW, Haller DG and Benson AR. Phase III study of gemcitabine in combination with fluorouracil versus gemcitabine alone in patients with advanced pancreatic carcinoma: Eastern Cooperative Oncology Group Trial E2297. J Clin Oncol. 2002;20:3270-3275. 